\title{
Sunlit fractions on urban facets: impact of spatial resolution and approach
}

Article

Accepted Version

Lindberg, F., Grimmond, C. S. B. and Martilli, A. (2015) Sunlit fractions on urban facets: impact of spatial resolution and approach. Urban Climate, 12. pp. 65-84. ISSN 2212-0955 doi: https://doi.org/10.1016/j.uclim.2014.11.006 Available at https://centaur.reading.ac.uk/38731/

It is advisable to refer to the publisher's version if you intend to cite from the work. See Guidance on citing.

Published version at: http://dx.doi.org/10.1016/j.uclim.2014.11.006

To link to this article DOI: http://dx.doi.org/10.1016/j.uclim.2014.11.006

Publisher: Elsevier

All outputs in CentAUR are protected by Intellectual Property Rights law, including copyright law. Copyright and IPR is retained by the creators or other copyright holders. Terms and conditions for use of this material are defined in the End User Agreement.

\section{www.reading.ac.uk/centaur}

\section{CentAUR}

Central Archive at the University of Reading

Reading's research outputs online 


\title{
Sunlit fractions on urban facets - Impact of spatial resolution and approach
}

\author{
Fredrik Lindberg ${ }^{1}$, C.S.B. Grimmond ${ }^{2}$ and Alberto Martilli ${ }^{3}$ \\ ${ }^{1}$ University of Gothenburg, Department of Earth Sciences, Box 460, SE-405 30 Göteborg, Sweden \\ ${ }^{2}$ Department of Meteorology, University of Reading, Earley Gate, PO Box 243, Reading, RG6 6BB, UK \\ ${ }^{3}$ Research Centre for Energy, Environment and Technology, CIEMAT, Edificio 70, P1.5, Avenida Complutense 22, \\ 28040 Madrid, Spain
}

\section{http://dx.doi.org/10.1016/j.uclim.2014.11.006}

Corresponding author: Fredrik Lindberg, fredrik.lindberg@gvc.gu.se

\begin{abstract}
The extent of the surface area sunlit is critical for radiative energy exchanges and therefore for a wide range of applications that require urban land surface models (ULSM), ranging from human comfort to weather forecasting. Here a computational demanding shadow casting algorithm is used to assess the capability of a simple single-layer urban canopy model, which assumes an infinitely long rotating canyon (ILC), to reproduce sunlit areas on roof and roads over central London. Results indicate that the sunlit roads areas are well-represented but somewhat smaller using an ILC, while sunlit roofs areas are consistently larger, especially for dense urban areas. The largest deviations from real world sunlit areas are found for roofs during mornings and evenings. Indications that sunlit fractions on walls are overestimated using an ILC during mornings and evenings are found. The implications of these errors are dependent on the application targeted. For example, (independent of albedo) ULSMs used in numerical weather prediction applying ILC representation of the urban form will overestimate outgoing shortwave radiation from roofs due to the overestimation of sunlit fraction of the roofs. Complications of deriving height to width ratios from real world data are also discussed.
\end{abstract}

Keywords: urban geometry, urban land surface model, LiDAR, shadow fraction algorithm, London 


\section{INTRODUCTION}

The modeling of exchanges (momentum, water vapor or energy) between the surface and the atmosphere is one of the key challenges for meteorological applications, whether pollutant dispersion, weather forecasting, or climate mitigation studies. For cities, full representation of the complexity of the urban form is constrained by computer resources and data availability, making the simplification of the three dimensional geometry a requirement. Grimmond et al. (2011) provide a detailed review of the range of simplifying assumptions made in state-of-the-art urban land surface energy balance models (ULSM), identifying three classes according to the level of detail represented, i.e. slab, single-layer and multi-layer models. The more sophisticated single and multi-layer schemes explicitly represent the urban form in two (or three) dimensions (2 or 3D).

To simulate shortwave energy input to the urban system, assumptions are needed to estimate how much solar radiation reaches the different facets: walls, roofs and roads (e.g. Arnfield 1982, Masson 2000, Martilli et al. 2002, Kusaka and Kimura 2004, Kanda et al. 2005, Harman and Belcher 2006, Krayenhoff and Voogt 2007, Schubert et al. 2012). The fractions of shaded and sunlit surfaces affect the distribution of the direct component of solar radiation, which is the dominant component of shortwave energy input, especially during clear weather situations. The complexity of the models varies from 'simple' where, for example, two perpendicular infinitely long canyons (ILC) are used Arnfield (1982), to 'more complex' where 3D representation of the surface is based on regular building arrays (Kanda et al. 2005). One common approach used within the single-layer urban canopy model (SLUCM) of Kusaka et al. (2001) and Kusaka and Kimura (2004) is to determine the portion of surface that is sunlit from a simple shadow casting algorithm in conjunction with a rotating ILC (Masson 2000, Chen et al. 2011, Lemonsu et al. 2012, Loridan and Grimmond 2012).

Detailed 3D geographical data for urban areas are becoming more widely available. Techniques such as aircraft mounted LiDAR (Light Detection Aperture Radar) make it possible to derive very high resolution digital surface models (DSM) that describe urban form (e.g. Goodwin et al. 2009, Lindberg and Grimmond 2011). This detailed information has been used in studies of urban climate (Lindberg 2007, Gál and Unger 2009, Martilli 2009 , Yu et al. 2009), human thermal comfort (Lindberg et al. 2008, Thorsson et al. 2011) as well as urban planning and architecture (Ratti and Richens 2004, Ratti 2005). The advantage of a high resolution DSM is as it is very close to a 'real world' representation of the urban environment it can be used to study detailed features and phenomena within the city. However, the high level of detail makes it computationally difficult to process very large areas such as whole cities.

The purpose of this paper is to examine how simplifications made with regards to urban form in a typical ULSM impact the representation of shadow patterns in a complex urban setting. This comparison is made from analysis of sunlit fractions derived from two different methods applied in the city centre of London: i) a simplified approach using an ILC as occurs in a number of ULSMs and ii) a more detailed approach using high resolution urban DSMs. ULSMs are typically used in meso- or larger area 3-D weather or climate forecasting model; whereas DSMs are typically used in micro- to local scale modelling for human comfort and urban planning. Here we analyse an area of 
central London (Figure 1) where both high resolution $\left(1 \mathrm{~km}^{2}\right)$ meso-scale simulations (e.g. Bohnenstengel et al., 2011; Chemel and Sokhi, 2012; Loridan et al., 2013) and detailed analyses of DSMs have been independently studied (e.g. Lindberg and Grimmond 2011).

\section{STUDY AREA AND SPATIAL DATA}

This study focuses on the Central Activity Zone (CAZ, Figure 1) of London, UK, an 'urban heat island action area' and key 'climate change adaptation strategy area' (GLA 2010). For SLUCM the analysis is conducted at $1 \mathrm{~km}$ horizontal resolution (see Figure 1); this is at the detailed end of the range of resolutions used in state of the art meso-scale modelling. A high resolution DSM was generated from building height and location data across the CAZ, derived from the vector dataset "Virtual London" which has ground elevation and building footprints including height attributes (Evans et al. 2006). Data were converted into a raster DSM with a pixel resolution of $4 \mathrm{~m}$. Typical ULSM model parameters, such as street width, building width and height, were used to estimate sunlit fraction in the ILC case. The Ordnance Survey MasterMap ${ }^{\circledR}$ Topography Layer (Ordnance Survey 2010) was used to derive the built fraction (the combined total of impervious surfaces plus building footprints) and the building area fraction or plan area index $\left(\lambda_{\mathrm{P}}\right)$, for each $1 \mathrm{~km}$ grid.

For the micro-scale analysis, an airborne LiDAR dataset obtained in the summers of 2005 and 2008 (Martin Holt (2011), Infoterra Ltd., personal communication) is used for an area in the CAZ (Figure 1). This dataset was processed and gridded at $1 \mathrm{~m}$ resolution, as described by Lindberg and Grimmond (2011). This higher spatial resolution LiDAR dataset allows more detailed analyses of shadow patterns and roof structures than the vectorbased Virtual London dataset as it assumes flat roofs. Figure 2 shows the difference between the two datasets around Westminster Abbey and Houses of Parliament.

With the coarser dataset the whole CAZ is examined, whereas only a sub-area is used for the more detailed analyses to keep times reasonable computationally. In this study, vegetation is excluded in the DSMs.

\section{IMPLICATIONS OF SCALE FOR URBAN MORPHOLOGY PARAMETERS}

Various degrees of simplification are required to describe the urban environment related to scales of application. These range from applications where the city is part of a region (e.g. meso scale weather forecast models or global climate models) with individual sub-units ( $10^{2}$ to $10^{4} \mathrm{~m}$ or much coarser) with drastically simplified parameters to architectural design and engineering for individual properties $\left(10^{-2}\right.$ to $\left.10^{0} \mathrm{~m}\right)$ where a close to 'real' world description is required. The trade-off between enhanced resolution, speed of analysis, and level of detail that would enhance the analyses has to be assessed in the context of the specific application. In this section, some of the implications are considered for the height to width $(\mathrm{H} / \mathrm{W})$ or aspect ratio parameter as determined from digital surface models (DSMs).

At coarser scales higher resolution processes typically are parameterized and therefore the details of the surface are simplified. Inconsistencies in the description in the urban geometry may arise because of this. If we 
consider an area just described by its height to width relation, widely used as a simplified measure of urban geometry, the ILC (e.g. Masson, 2000, Kusaka et al., 2001), an area of cubes or building blocks (e.g. Kanda et al. 2005, Krayenhoff and Voogt 2007) and a high resolution DSM will all have different areal fractions. For example, if the ILC has a H/W =of 1.0, the plan area index ( $\lambda_{P}$, or area of buildings) is 0.5 (Figure 3a), whereas for cubes the $\lambda_{P}$ is 0.25 (Figure $3 b$ ), and for a near 'real' world case (i.e. using a high resolution DSM) it could be a range of values (e.g. Figure 3c).

Further complications arise when determining the H/W ratio for an area (e.g. $1 \mathrm{~km}^{2}$ ) from detailed surface information, e.g. a DSM, as it can be done in multiple ways. For a canyon with two buildings (here for simplicity we will treat the objects as buildings) of equal height on either side, the width of the 'street' (again for simplicity the space between the objects is referred to as a street) is perpendicular to the two buildings.

One method is to calculate a mean building height $\left(\overline{Z_{B}}\right)$ and a mean street width $\left(\overline{w_{S}}\right)$ giving:

$$
H /_{W}=\frac{\overline{Z_{B}}}{\overline{W_{S}}}
$$

To derive $\overline{Z_{B}}$, from a high resolution DSM, all pixels identified as building within the area of interest have their height values averaged (e.g. Figure $4 a)$. To objectively derive $\overline{w_{S}}$ spatial analysis algorithms are required. This study makes use of 'distance allocation algorithms' common in most GIS-software packages. First the Euclidian distances from buildings are determined, then local maxima are identified. These will be located in-between two (or more) buildings (Figure 4c). Then the distance is multiplied by two to get street width for a particular location (pixel) as shown in Figure 4c. To obtain $\overline{w_{S}}$, all street widths are averaged within the area of interest. Other methods also exist to derive $\overline{w_{S}}$, see for example the approach described by Schubert and Grossman-Clarke (2013) who calculate $\overline{W_{S}}$ as the average of a weighted average distance between walls in the four cardinal directions.

Alternatively, individual street segment $(i)$ width and its adjacent building segment height can be averaged for all street segments within the areal extent in question:

$$
[H / W]_{i}=\left[\sum_{i=1}^{n} \frac{z_{B(i)}}{w_{S(i)}}\right] n^{-1}
$$

For each $i$ location (pixel) identified as a local distance maxima between building objects, the height information of the building edges $z_{B(i)}$ are allocated to the pixels of local distance maxima. A $3 \times 3$ mean kernel filter is used to incorporate different building heights. The allocated building height (Figure 4b) is divided by the street width

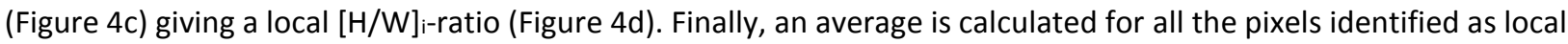
maxima pixels within the area of interest. A distance location algorithm identifies the local maxima pixels, and these pixels are used to calculate the local $[\mathrm{H} / \mathrm{W}]_{\mathrm{i}}$-ratio (Figure $4 \mathrm{~d}$ ) from the information given in Figure $4 \mathrm{a}$. In order to perform the calculations required in Eq. 2, flat roofs are assumed as the height allocated is the building edge pixels. The Virtual London dataset, mainly used in this study (section 2), was prepared by assigning all pixels the mean height within each building footprint to ensure the correct height for Eq.2 is used.

A complication in deriving street widths arises in open areas (e.g. parks, water bodies). The local distance maxima algorithm usually identifies several locations resulting in a 'fishnet structure' (compare the central open 
space in Figure 4a and c). This will affect the average H/W-ratios in those areas where large parks etc. are found (see below in this Section).

Eq. 1 produces slightly higher values of H/W compared to Eq. 2 (Figure 4e). The advantage of the Eq. 2 method is that the distribution of local H/W values within each area (i.e. $1 \mathrm{~km}^{2}$ grid in this study) can be determined (Figure 4f). The distribution is clearly positively skewed (in this study area), with a larger frequency of low local $\mathrm{H} / \mathrm{W}$-ratios, especially in grids with a low mean $\mathrm{H} / \mathrm{W}$ as derived using Eq. 1. (A normally distributed dataset should have a symmetric S-shaped form). This is no table for areas with a mean H/W close to 0 (Eq. 1, dark blue in Figure 4f). Based on the skewness evident in Figure $4 \mathrm{f}$, there is a closer 1 to 1 relation between the median values derived for each grid using Eq.2 and mean H/W derived from Eq. 1 (Figure 4e); the median values are consistently lower than the mean values derived using Eq. 2. This suggests that a distribution related characteristics may be more useful for characterising larger areas (skewness, kurtosis, median IQR, than through the mean.

Thus the question of how to derive and define the H/W-ratio for large open area using Eq. 1 and/or 2 still remains. For example, a large rectangular open area surrounded by buildings could, for example, be described as a street in 'two' directions with two different H/W-ratios (one in each direction). Similarly problematic is the calculation of the H/W-ratio for street intersections. Here the widths for intersection are derived based on the distance allocation approach resulting in different widths within a street intersection (Figure 4c). Thus, it is likely different results will be obtained between analysts and a definitive method is lacking. Another approach to derive $\mathrm{H} / \mathrm{W}$-ratio uses the simplified ILC, representative of the real morphology in terms of conserving fluxes of heat and momentum, the ILC is represented by one road, one roof and two walls (Martilli 2009). This, it is reasonable to assume, that the simplified morphology should have the same areal fractions of the three components as the real morphology. From this reasoning the fraction of the roof area $\left(\lambda_{P}\right)$ and wall area $\left(\lambda_{w}\right)$, respectively in the case of the real morphology are:

$$
\begin{aligned}
& \lambda_{P}=\frac{\text { Area }_{\text {road }}}{\text { Area }_{\text {road }}+\text { Area }_{\text {roof }}} \\
& \lambda_{W}=\frac{\text { Area }_{\text {wall }}}{\text { Area }_{\text {road }}+\text { Area }_{\text {roof }}}
\end{aligned}
$$

In the case of the ILC the two fractions can be written as:

$$
\begin{aligned}
& \lambda_{P}=\frac{\text { Width }_{\text {road }}}{\text { Width }_{\text {road }}+\text { Width }_{\text {roof }}} \\
& \lambda_{W}=\frac{2 H}{\text { Width }_{\text {road }}+\text { Width }_{\text {roof }}}
\end{aligned}
$$

Making use of equations 5 and 6, a H/W-ratio for a simple 2D (ILC) derived using real morphology information is derived (Martilli 2009):

$$
H / W=\frac{\lambda_{W} \lambda_{P}}{2 \lambda_{P}\left(1-\lambda_{P}\right)}
$$

Deriving wall area from high resolution DSMs is not trivial (see Appendix 1).

Comparison of the method described in Eq. 1 and that in Eq. 7 is shown in Figure 5. The two methods are similar but $\mathrm{H} / \mathrm{W}_{\mathrm{Eq} .} 7$ give slightly larger values for $\mathrm{H} / \mathrm{W}$ greater than 0.5 and smaller values for $\mathrm{H} / \mathrm{W}$-ratios less than 
0.5. The discrepancies between the two methods are due to differences found in the width parameter. Areas with very small H/W-ratio, which usually is a result of very large widths (e.g. areas including large park areas etc.) seems not to be captured by the method derived using Eq. 1.

The H/W-ratio is often used as the descriptor of urban geometry to calculate other parameters such as the complete surface or total areal fraction of each facet (viz., road, walls and roofs). However, the H/W-ratio itself does not have an areal extent or relate to a roof area. A parameter such as sunlit fraction $\left(F_{S}\right)$ based on $\mathrm{H} / \mathrm{W}$-ratio, can be defined based on multiple characteristics, such as the total sunlit fraction of all surfaces combined, or separately for each surface. Treating the road and roof facets separately permits simple fraction of the sunlit surface for each facet. Walls, however, require assumptions about orientation of the canyons. An ILC, with only two walls opposite each other can never have a wall sunlit fraction greater than $50 \%$. Generally, the total sunlit fraction $\left(F_{S, T}\right)$ can be defined:

$$
F_{S, T}=\frac{A_{\text {roof }, s}+A_{\text {road }, s}+A_{\text {wall }, s}}{A_{\text {roof }, T}+A_{\text {road }, T}+A_{\text {wall }, T}}
$$

The total area $\left(A_{\text {facet } T}\right)$ of the facets considered becomes key. Thus, for an ILC there is one roof, one road and two walls.

\section{SUNLIT FRACTIONS DERIVED FOR AN ILC}

The simplified geometry employed by some urban canopy models allows a representation of sunlit and shadow portions of the roof, road and wall areas. In the Kusaka et al. (2001) SLUCM, solar geometry is computed on an hourly basis and the sun beam is intersected with ILCs aligned in 8 different directions $(\pi / 8, \pi / 4,3 \pi / 8, \pi / 2$, $5 \pi / 8,3 \pi / 4,7 \pi / 8$ and $\pi$ ) using the equations given in Kusaka et al. (2001) and Loridan and Grimmond (2012; see their Fig. 3 and 4).

The shadow patterns, which vary through the day and year, are illustrated for an ILC with a H/W=1 in Figure 6 for June $21^{\text {st }}$ (day of year, DOY $=172$ ) in London $\left(51^{\circ} 30^{\prime} 28^{\prime \prime} \mathrm{N}, 00^{\circ} 07^{\prime} 41^{\prime \prime} \mathrm{W}\right.$ ). The longest solar day gives the widest range with respect to solar azimuth and elevation. For an ILC the roof is always sunlit during daytime. On June $21^{\text {st }}$, the sunlit fraction of the walls increases until 9 am. From 9 am to $3 \mathrm{pm}$, with the sun elevation greater than $45^{\circ}$, one of the two canyon walls is completely sunlit, causing wall fraction to be a constant 0.50 . Subsequently it decreases until sunset. The road sunlit fraction peaks, as expected, at noon. The total sunlit fraction (eq. 8) has a sharp increase (decrease) at sunrise (sunset) due to the large sunlit fractions on the roof throughout the daytime. In this example, $F_{S, T}$ (London canyon, $\mathrm{H} / \mathrm{W}=1, \mathrm{DOY}=172$ ) peaks at noon with similar values as sunlit road fractions.

\section{GENERATION OF SHADOW PATTERNS ON URBAN DSMS}

To derive detailed shadow patterns on all facets for a large area (e.g. Greater London), the spatial resolution of a DSM needs to be relatively coarse. However, the shadow patterns on a wall are impacted by the shape of the wall and thus the spatial resolution with its associated detail. Thus in this study a small area is 
analysed at $1 \mathrm{~m}$ resolution to assess the (total and individual facets) sunlit fractions (section 6.2.2). A vector based solution to derive shadows has vast computational cost which is prohibitive at the whole city area extent (as used in the paper). Even the smaller model domain used here at $1 \mathrm{~m}$ resolution is probably too large to undertake shadow calculations in a vector based approach.

To generate a shadow on a high resolution urban DSM representing a 'real' world urban setting, the altitude and azimuth of a distant light source (the Sun) are specified. Following Ratti and Richens (1999), 'shadow volumes' are computed by sequentially moving the raster DSM at the azimuth angle of the Sun, reducing the height at each iteration based on the Sun's elevation angle. At each iteration a part of the shadow volume is derived and by taking the maximum of this volume for each iteration the whole shadow volume is built up. This is stored as a new DSM. The map of shadows is determined by subtracting the shadow volume image from the original DSM. A Boolean image is produced where pixels with a negative or zero value are those exposed to sunlight and given a new value of 1 , and positive values which are in shade are given a new value of 0 . For a detailed description of the shadow casting algorithm (SCA) is provided by Ratti and Richens (2004) or Lindberg and Grimmond (2010).

To derive sunlit fractions on walls, a modified version of the SCA is used. It is relatively straightforward to obtain the height of the shadow when it hits a building wall using an ordinary edge detecting filter (see Appendix 1) to identify wall pixels. By dividing the total wall height with the shadow height, the fraction of shadowed wall for each wall pixel is determined (inverse of the sunlit fraction). A wall section is considered to be shadowed if the sun beam falls oblique to that section. This is determined by computing an aspect grid from all wall pixels and comparing it with Sun azimuth. For example, a test casting a shadow from a sun position of $45^{\circ}$ altitude and $180^{\circ}$ azimuth using an infinite East-West canyon $(\mathrm{H} / \mathrm{W}=2$ ) resulted in a sunlit wall fraction of 0.25 (south wall in shadow and $50 \%$ of the north wall sunlit). One important factor in deriving accurate sunlit factions on walls is the spatial resolution of the DSM used. A coarse resolution DSM introduces biased results as walls are offset by the pixel resolution of the DSM (Figure 2). Therefore, the wall sunlit fraction is only derived using the $1 \mathrm{~m}$ resolution DSM.

\section{SUNLIT FRACTION RESULTS}

\subsection{Infinitely Long Canyon Comparison}

First, a comparison between the two schemes, SLUCM and SCA, is performed for an ILC with various H/W-ratios. A $2500 \mathrm{~m}$ long and $50 \mathrm{~m}$ wide canyon at a pixel resolution of $1 \mathrm{~m}$ is gridded and used as input in the SCA method. Building height is altered to create $\mathrm{H} / \mathrm{W}$-ratios of $0.5,1$ and 2 . A cross section transect in the middle of the model domain $(1250 \mathrm{~m})$ is used to derive the shadow patterns. The results for the two different methods are virtually identical for the shadow fraction roofs (mean bias error $(\mathrm{MBE})=0)$, walls $(\mathrm{MBE}=-0.00002)$ and ground $(\mathrm{MBE}=-$ 0.0001).

The difference in computation time (i.e. computation complexity) between the two schemes is significant and not applicable for comparison since the fundamental dimensions between the two schemes is different. The two dimensional SCA has a main computation complexity of order $O^{n}$ where $\mathrm{n}$ is the number of pixels; that is changing 
the number of rows and columns (by for example increasing the spatial resolution from $1 \mathrm{~m}$ to $0.5 \mathrm{~m}$ ) increases computation time four fold (Lindberg 2005). The notation $O$ allows us to describe the behaviour of the relationship between computational time (or space) and input size, without being precise about the scalar multipliers. The algorithm also has a second complexity of $O^{*} m$, where $\mathrm{m}$ here is the difference between the minimum and maximum height within the DSM used. Hence, the computation time and computer resources used to compute sunlit fractions to be used over large areas (e.g. within individual grids for the domain of a meso-scale model) is not applicable using the SCA. Whereas the much simpler zero dimensional SLUCM scheme can be used in a fraction of the time compared to the SCA.

\subsection{Real world comparison}

With confirmation that the two schemes produce identical results for the ILC case, the sunlit fractions determined with the SLUCM and SCA for 21 June (DOY=172) for all of the $72,1 \mathrm{~km}^{2}$ grid cells that constitute the CAZ (section 6.2.1) are compared, and then two $1 \mathrm{~km}^{2}$ grids are compared at $1 \mathrm{~m}$ resolution (section 6.2.2). Height to width ratio input to the SLUCM scheme is derived from the $4 \mathrm{~m}$ resolution DSM representing the real world case using Eq. 7. This equation has been chosen because, for the main application of the SLUCM (estimate of the heat fluxes in an atmospheric model), the conservation of the actual area of the different surfaces is an essential property. As urban geometry, such as building height and road width, influences the sunlit fractions the variability within the CAZ are explored. Examining the relation between mean building height $(\mathrm{zH})$ and variability of building heights $\left(\mathrm{ZH}_{\mathrm{H}} \mathrm{s}\right)$ ) (Figure $\left.7 \mathrm{a}\right)$, it is evident that higher $\mathrm{ZH}_{\mathrm{H}}$ are associated with higher standard deviations in $\mathrm{ZH}_{\mathrm{H}}$. The same is evident comparing $\mathrm{z}_{\mathrm{H}}$ and $\mathrm{H} / \mathrm{W}$-ratio (Figure $7 \mathrm{~b}$ ). The distribution of $\mathrm{z}_{\mathrm{H}}$ across the $72,1 \mathrm{~km}^{2}$ grids (Figure $7 \mathrm{c}$ ) has a mean of $13.2 \mathrm{~m}$ whereas the most common building height is in the $10.3-11.5 \mathrm{~m}$ range.

There is a clear relation between $\lambda_{p}$ and $\mathrm{H} / \mathrm{W}$-ratio derived using Eq. 7 (Figure $7 \mathrm{~d}$ ), with more dense urban structures having higher $\mathrm{H} / \mathrm{W}$-values. If comparing $\mathrm{H} / \mathrm{W}$-ratio derived using Eq. 1, the scatter is increased (not shown), especially for low $\lambda_{P}$, and is probably explained by the widths calculation used in Eq. 1 (see section 3). Despite the focus on the centre of a megacity (London), the variations in surface characteristics are large. Within this area the majority of Stewart and Oke's (2012, their table 3) 10 built Local Climate Zones (LCZ) are represented based on the H/W-ratios, $\lambda_{P}$ and $z_{H}$ surface characteristics. The Compact high-rise $\left(L C Z 1 ; H / W>2, Z_{H}>25, \lambda_{P}=0.4-0.6\right)$ as well as the Lightweight low-rise $\left(L C Z 7 ; H / W>1-2, Z_{H}>2-4, \lambda_{P}=<0.4\right)$ is not represented within the model London study area.

\subsubsection{Sunlit fractions throughout the CAZ}

The sunlit area on the canyon floor (i.e. roads etc.) related to the full horizontal area (roads+roofs) in all the 72 grid cells for DOY 172 (21 June) are shown in Figure 8. Given that the full horizontal area (roads+roof) is one kilometre square for all the grid cell, the sunlit fraction on roads (roof) can be seen also as the actual sunlit area on road (roof) expressed in square kilometres. The SLUCM scheme reproduces the diurnal pattern of the shadow 
algorithm (Figure $8 \mathrm{a}$ cf. $8 \mathrm{~b}$ ). When the $\lambda_{\mathrm{p}}$ is smallest (i.e. highly vegetated and/or open), there is a strong contrast between mornings/evenings and the middle of the day with regards to the daily pattern of sunlit on roads.

Whereas for areas with larger $\lambda_{P}$ values this transition is more gradual. The SLUCM scheme is able to capture these gradual transition patterns well (Figure 8b). As the SLUCM uses the H/W to calculate the sunlit fraction there is a strong relation between $\mathrm{H} / \mathrm{W}$ ratios and sunlit fraction (Figure 8c). The SCA method is able to capture skewness in the sunlit fractions as the shadow is generated from real urban morphology. This can be detected for some of the 1 $\mathrm{km}^{2}$ grids which experience either high sunlit fraction in mornings or evenings. This phenomenon can occur when e.g. half of a $1 \mathrm{~km}^{2}$ grid is open whereas the other half is build up. These skewed pattern are not found in the SLUCM scheme. The impact on radiation fluxes occurs when the shortwave radiation is relatively low so depending on application maybe small. When the components facets are normalized by the total horizontal areas (roads+roofs), the general pattern on road is correctly reproduced (Figure 8). However, a systematic underestimation by the SLUCM is evident, as average daytime errors in sunlit fractions (SCA $4 m$ - SLUCM) as high as 7.6\% occur for individual specific grid cells. The limitation of canyon orientations to eight (here) for SLUCM, accentuates this for specific orientations. However, the sunlit fraction could also be related to other area fractions. Not unexpectedly, when the road sunlit fraction is normalized by road area only (Figure 9a), roads and roofs (Figure 9b) and the total urban area (roads, roofs and walls) (Figure 9c) the sunlit fractions are reduced. The largest reduction is for the densest areas where the areas of the roofs and the walls are the greatest. For the most open areas, the reduction is much smaller. In the remainder of this section the sunlit fractions are related to the total horizontal (plan) area represented by the roofs and the roads $\left(1 \mathrm{~km}^{2}\right)$.

Sunlit fractions on roofs (Figure 10) have a different pattern to roads. Firstly, the SLUCM scheme is constant even though the urban form and fraction is changing as the roofs are treated as flat and sunlit throughout the day, and all the buildings have the same height. This simplification ignores that a roof can be shadowed by adjacent buildings as well as from structures on the roof itself (e.g. tilting roofs). The Virtual London dataset (4 $\mathrm{m}$ resolution) also has flat roofs, but it considers buildings of different height. The pattern shows clearly that the roofs get shaded by other objects (buildings) nearby; hence, the lower sunlit fractions in the morning and evening for all grids within the study area (Figure 10). However, note that the SCA calculations in this study are made for the whole model domain simultaneously so shadows could originate from adjacent $1 \mathrm{~km}^{2}$ grid cells. Although real, these would not be captured if the calculation were done in separate $1 \mathrm{~km}^{2}$ grids.

There is a clear relation between increasing $\mathrm{H} / \mathrm{W}$-ratio and decreasing sunlit fractions on roofs (Figure 10b). As shown in figure $7 \mathrm{a}$ and $7 \mathrm{~b}$, grids with higher $\mathrm{H} / \mathrm{W}$ are also those with higher values of building height standard deviation. This indicates that denser urban environments with large building height variability generate shadow patterns that produce shade to adjacent objects to a greater extent compared to less dense areas with more uniform building heights. The SLUCM systematically overestimates the sunlit fractions on roofs relative to the SCA method with a high resolution DSM, especially in the mornings and evenings where the overestimation can be as high as $50 \%$ (Figure 11). However, during noon, when sun altitude is relatively high and only very small roof areas 
are shadowed by adjacent objects, the sunlit fractions are almost similar. On a daily average (DOY=172), this overestimation could be as high as $12.4 \%$, with a probable further overestimation on days with lower sun altitude angles. The MBE for sunlit fractions on roads as well as roofs (SCA $4 m$ - SLUCM) related to total horizontal area (roofs+roads) for all the $72,1 \mathrm{~km}^{2}$ grids are shown in Figure 12 . There is a general overestimation of sunlit fraction on roads and underestimation for the roofs, with the absolute values being higher for roofs. There is strong relation between increased MBE of sunlit fractions on roofs related to increased H/W-ratio and $\lambda_{\mathrm{p}}$ whereas this is not evident for the roads.

\subsubsection{Sunlit fractions using very high resolution DSMs}

Although the Virtual London dataset gridded at $4 \mathrm{~m}$ resolution is very detailed with regards to urban geometry (ground and building heights), features such as the distribution of flat roofs still simplify the 'real world' urban environment. To increase the accuracy of the urban geometry and form even further, the GLA LiDAR dataset gridded at $1 \mathrm{~m}$ resolution (see section 2) was analysed for two $1 \mathrm{~km}^{2}$ grids within the CAZ (Figure 1): 6D, a dense urban area $\left(\mathrm{H} / \mathrm{W}\right.$-ratio $\left.=1.06, \lambda_{P}=0.49\right)$, and $6 \mathrm{E}$ an area of much lower density $\left(\mathrm{H} / \mathrm{W}\right.$-ratio $\left.=0.27, \lambda_{P}=0.23\right)$ due to both the inclusion of the river Thames and a few larger building complexes such as Waterloo railway station. The most noticeable difference between the 4 and $1 \mathrm{~m}$ resolution datasets is that the latter includes roof structures such as chimneys and tilting roofs that can produce shadows on that same roof, which is not possible when considering just flat roof surfaces (Figure 2). The red shadowed areas (Figure 2) generated using the SCA are for $16: 00$ on the $21^{\text {st }}$ June (DOY=172). On buildings with very complex roof structures the difference between the two DSMs is very noticeable. See, for example, Westminster Abbey at the centre of the two maps.

Comparing the sunlit fraction on roads (DOY=172) related to the total urban area using SLUCM and SCA (4 and 1 $m$ resolution DSM) schemes for grid cells 6D and 6E, the values are similar as expected (Figure 13a), despite increased detail from use of the $1 \mathrm{~m}$ resolution dataset. As shown in Section 6.2.1, the denser grid (6E) deviates more between the SLUCM scheme and the SCA. The enhanced shadow details cause the sunlit fraction of roofs to decrease with the higher resolution DSM (Figure 13b) by more than $10 \%$ near midday and even more during early mornings and evenings. The denser urban grid cell (6D) shows the largest decrease between the two datasets (Figure 13b).

With the very high resolution DSM it is possible to examine sunlit fractions on building walls without introducing too much bias due to pixel resolution (see section 5). Sunlit wall fraction curves (Figure 13c) from SLUCM and SCA are very different, especially around noon, with the simplification of the ILC becoming evident. When the angle created by the H/W-ratio becomes lower than the sun altitude angle, one wall is always sunlit, resulting in a constant sunlit fraction of 0.5 . Using the SCA with the high resolution DSM the sunlit fraction increases to a maximum at noon followed by a decrease. This could be explained by the complexity of the 'real-world' with buildings of various heights and shapes. Here, an edge detecting filter is applied and differences greater than $3 \mathrm{~m}$ between two adjacent pixels are considered a wall (see Appendix 1). This does mean that other features such as 
river banks and other topographic feature can also be identified as building walls. The denser grid shows (6D) higher values of sunlit fractions on the wall since the wall area is much greater in the denser grid. There is an evident underestimation of sunlit walls for both grids.

To derive the total sunlit fraction $\left(F_{S, T}\right)$ for a specific grid cell, the actual total surface area of the three components (roads, roofs and walls) need to be considered. This means, for example, that a high roof sunlit fraction can have a minor effect if the total surface area of the roofs is small. Note that the roof area is assumed to be the plan area and so excludes the additional areas from other components (e.g. sloped or dormer). For the two $1 \mathrm{~km}^{2}$ grid cells in Figure 13 (6D and 6E), the total area of each surface is shown in Table 1 at $4 \mathrm{~m}$ resolution. The larger built fraction of 6D is from both roads and roofs compared to $6 \mathrm{E}$ which is dominated by roads but also includes water. The wall area for 6D is more than twice as large as any of the two other surfaces within that grid, but the less dense $6 \mathrm{E}$ has half the wall area. Thus, the sunlit fraction on walls will dominate the calculation of total fraction in this grid. Since the SLUCM scheme represents the urban morphology as an ILC, the dimensions of the three facets are needed (expressed in $\mathrm{m}^{2}$ Table 1).

The total fraction of each urban facet that could be exposed to direct sunlight throughout a day is shown in Figure $13 \mathrm{~d}$. When the two methods (SLUCM and SCA) are compared the shape is similar but SLUCM overestimates in mornings and evenings. The SLUCM results are very much influenced by the continuously sunlit roof. This is more evident in the dense urban grid (6D) with the larger roof area (Table 1), especially during mornings and evenings. The overestimation of sunlit walls during mornings and evenings contribute to overestimation of $F_{S, T}$ at these time periods. There is also an overestimation by SLUCM throughout the middle of the day (Figure 13d) for the denser grid cell (6D), whereas the less dense grid yields very similar values compared to the SCA (6E). This is very much dependent on the proportions shown in Table 1 in conjunction with the calculated sunlit fractions, especially for the SCA method. Two adjacent grids (5D and 5E in Figure 1) included in the domain of the GLA LiDAR dataset (Figure 1) were also examined (not shown) and showed similar results to 6D and 6E.

\section{IMPLICATIONS AND CONCLUSIONS}

The interaction between the surface and the atmosphere is key to most meteorological applications, ranging from weather forecasting to pollutant dispersion and boundary layer height modeling. Simplifications are required in models to capture the complexity of an urban environment to simulate radiation exchange processes and the surface energy balance of cities. Two different methods to derive sunlit fractions are compared: the SLUCM with an ILC, and the more complex SCA method which uses high resolution DSMs. With a simple 3D canyon structure the SLUCM is able to represent the overall variability in sunlit patterns generated by a complex urban environment like London's CAZ, but several limitations are identified:

- Sunlit fractions on roads are well represented by an ILC scheme but show a minor underestimation.

- Sunlit fractions on roofs are constantly overestimated by an ILC scheme because all the buildings have the same height, and a flat roof surface. Even using the DSM with flat roofs, this underestimation is evident due 
to the inability of the SLUCM to account for shading from adjacent buildings. The differences are highest during early mornings and late evenings. Overestimation is highest for dense urban areas (i.e. high H/Wratio and/or high $\lambda_{P}$ ). Using a DSM where roof structures are included (e.g. tiled roofs and chimneys etc.) further accentuates this overestimation.

- Indications that sunlit fractions on walls are overestimated assuming an ILC during mornings and evenings are found. This can be explained by the difference in complexity between the two schemes where the 'realworld' case consists of buildings with various heights and shapes which create a higher proportion of shadows when the sun angle is low.

- $\quad$ The total sunlit fraction $\left(F_{S, T}\right)$ is very sensitive to the actual urban morphology and the relation between the actual areas of roads, roofs and walls. Nevertheless, the SLUCM scheme is able to estimate and capture $F_{S, T}$ reasonably accurately using a very simple representation of the urban environment with a simple ILC. If the three components (walls, roofs and roads) are considered separately, large errors are found.

The implications of these errors are dependent on the application targeted. For example, urban land surface models used within numerical weather prediction models frequently use a simple representation of the urban form; they will overestimate area directly sunlit and therefore impact the radiative exchanges, this error will cascade through the model calculations. Since in the SLUCM walls, roofs and roads have different albedo and thermal properties, these errors may impact the total energy budget.

The computational cost of calculating sunlit fractions on walls using a high resolution dataset is very high and therefore only the four grid cells completely included in the CAZ domain were examined. However, high resolution datasets are required in order to obtain reasonable results when estimating sunlit wall fractions since a coarse resolution DSM introduces biased results as walls are offset by the pixel resolution of the DSM. It is therefore recommended that future research should include a larger very high resolution dataset (1 m pixel resolution) to derive a better understanding on how the $F_{S, T}$ vary within an urban environment.

To improve the accuracy of sunlit fractions used in urban weather/climate models, attention should be directed to roofs and walls. Simpler urban land surface models will be biased by the solar incidence angle (higher during mornings and evenings) as there will be an overestimation of shortwave energy fluxes. More complex representation of the urban form may also improve the sunlit fractions on walls (e.g. Kanda et al. 2005).

The variability of building heights within each grid cell plays a significant role for the shadow fractions on roofs. As indicated in this study the relation between mean building height and variations of building height is high.

However, the scatter indicates that using only mean building height as a parameter to determine surface roughness could be misleading. Similarly sunlit fractions of roofs determinations could be improved by making use of knowledge of the varying heights (e.g. Schubert et al. 2012) but until tested it is not possible to determine if an overestimation of sunlit fractions on walls during mornings and evenings remains or not.

\section{Acknowledgements}


The Virtual London and the Greater London Authority LiDAR dataset are and used courtesy of Matthew Thomas (Greater London Authority) from a NERC/ARSF (GB08/19) flights which is acknowledged. Additional financial support was provided by NERC ClearfLO (NE/H003231/1), EU emBRACE (FP7-ENV-2011 283201), NERC/Belmont TRUC NE/L008971/1, G8MUREFU3FP-2201-075), FORMAS - the Swedish Research Council for Environment, Agricultural Sciences and Spatial Planning and H2020-EO-1-2014 Project 637519: URBANFLUXES.

\section{APPENDIX 1: ESTIMATING WALL AREAS FROM GEODATA}

As described in Section 3, the technique to estimate wall area from geodata is an important issue for a variety of urban land surface parameters. Based on the data format (i.e. vector or raster), different approaches need to be applied. For a vector dataset, the topological structure or the accuracy of the data are of absolute importance. Vector data ideally consist of a building footprint polygon (or polyline) layer with height information embedded in the object structure alternatively included in appurtenant attribute tables. Using vector data with full roof structures description (i.e. including objects such as chimneys etc.) makes it very complicated to derive wall areas and conversion to a raster dataset is recommended (see below). The accuracy of the vector data becomes especially important where different building segments are located at the same position (e.g. two attached buildings). Those segments need to represent the difference in height between the two building roofs (Figure A1a). This type of information is extremely rare and needs to be derived using geoprocessing techniques (Figure A1b). Thus, when a vector dataset such as presented in Figure A1b is available, the areas of the walls for a specific horizontal area could be derived (Figure A1b).

If a high resolution DSM is used it is essential to use appropriate methods in order to assign the correct number of pixels to represent wall. Figure A2 (left) gives an example of how pixels are assigned using vector to raster conversion tool in ArcGIS 10.2 (ESRI). Using this tool, as well as other similar tools, too many pixels are assigned as walls and thus, the wall area will be overestimated. One solution is instead to apply a 4-directional $3 \times 3$ kernel majority filter on a DSM and then identify the differences between the original DSM and the raster produced by the filtering process. By setting a threshold limit of the height that should represent a wall (e.g. 3 m), wall pixels are identified (Figure A2, right). One important issue when using raster based data is not to alter the wall area as pixel resolution is changed. The wall area has to be multiplied by the pixel length. For example, using a $4 \mathrm{~m}$ resolution raster dataset, the wall area is calculated as the sum of pixel values (height in meter) * 4 (pixel resolution in meter). A comparison between different geodata formats and pixel resolution for the $721 \mathrm{~km}^{2}$ grids is shown in Figure A3. Using the Virtual London (VL) vector data produces slightly higher values compared to the $4 \mathrm{~m}$ VL raster (Figure A3, left). The reason for this is probably that walls lower than $3 \mathrm{~m}$, which was used as the threshold value for identifying a wall, is included in the vector dataset. This threshold should be changed based on application and urban structure (e.g. suburban or $\mathrm{CBD}$ ). Comparing the VL raster data with a resampled (nearest neighbour) raster data based on the $1 \mathrm{~m}$ LiDAR dataset from Greater London Authority (GLA) show almost similar results. Figure A3 (right) compares the GLA dataset when pixel resolution has been changed and shows that wall areas are almost 
preserved as pixel resolution is altered. The small difference could be explained due to the fact that the level of detail is reduced when decreasing the resolution, e.g. a very small canyon could disappear as the spatial resolution is reduced.

Table 1: Characteristics of the two $1 \mathrm{~km}^{2}$ cells analysed in detail within the Central Activity Zone in London, UK. The numbers in parentheses gives the percentages of the total surface (roads, roofs and walls). For grid location see Figure 1.

\begin{tabular}{|c|c|c|c|c|c|c|}
\hline & \multicolumn{4}{|c|}{ DSM (4 m resolution) } & \multicolumn{3}{c|}{ SLUCM } \\
\hline $\begin{array}{c}\text { Grid } \\
\text { ID }\end{array}$ & $\begin{array}{c}\text { Roof area } \\
\left(\mathrm{km}^{2}\right)\end{array}$ & $\begin{array}{c}\text { Road area } \\
\left(\mathrm{km}^{2}\right)\end{array}$ & $\begin{array}{c}\text { Wall area } \\
\left(\mathrm{km}^{2}\right)\end{array}$ & $\begin{array}{c}\text { Roof width } \\
(\mathrm{m})\end{array}$ & $\begin{array}{c}\text { Road width } \\
(\mathrm{m})\end{array}$ & $\begin{array}{c}\text { Wall height } \\
(\mathrm{m})\end{array}$ \\
\hline 6D & $0.491(23 \%)$ & $0.509(24 \%)$ & $1.083(53 \%)$ & 17.7 & 18.4 & 19.6 \\
\hline 6E & $0.234(17 \%)$ & $0.766(54 \%)$ & $0.418(29 \%)$ & 21.2 & 69.3 & 18.9 \\
\hline
\end{tabular}

\section{REFERENCES}

Arnfield, A. J. (1982) An approach to the estimation of the surface radiative properties and radiation budgets of cities ( Columbus, Ohio). Physical Geography, 3, 97-122.

Bohnenstengel, S.I., Evans, S., Clark, P.A. and Belcher, S.E., 2011. Simulations of the London urban heat island. Quarterly Journal of the Royal Meteorological Society, 137(659): 1625-1640.

Chemel, C. and Sokhi, R.S., 2012. Response of London's Urban Heat Island to a Marine Air Intrusion in an Easterly Wind Regime. Boundary-Layer Meteorology, 144(1): 65-81.

Chen, F., H. Kusaka, R. Bornstein, J. Ching, C. S. B. Grimmond, S. Grossman-Clarke, T. Loridan, K. W. Manning, A. Martilli, S. Miao, D. Sailor, F. P. Salamanca, H. Taha, M. Tewari, X. Wang, A. A. Wyszogrodzki \& C. Zhang (2011) The integrated WRF/urban modelling system: development, evaluation, and applications to urban environmental problems. International Journal Of Climatology, 31, 273-288.

Evans, S., A. Hudson-Smith \& M. Batty (2006) 3-D GIS; Virtual London and beyond. An exploration of the 3-D GIS experience involved in the creation of Virtual London. Cybergeo : European Journal of Geography. Sélection des meilleurs articles de SAGEO 2005, document 359.

Gál, T. \& J. Unger (2009) Detection of ventilation paths using high-resolution roughness parameter mapping in a large urban area. Building And Environment, 44, 198-206.

GLA (2010) Greater London Authority. The draft climate change adaptation strategy for London. http://www.london.gov.uk/climatechange/sites/climatechange/staticdocs/Climiate_change_adaptation.p df, pp 138.

Goodwin, N. R., N. C. Coops, T. R. Tooke, A. Christen \& J. A. Voogt (2009) Characterizing urban surface cover and structure with airborne lidar technology. Canadian Journal of Remote Sensing, 35, 297-309.

Grimmond, C. S. B., M. Blackett, M. J. Best, J. J. Baik, S. E. Belcher, J. Beringer, S. I. Bohnenstengel, I. Calmet, F. Chen, A. Coutts, A. Dandou, K. Fortuniak, M. L. Gouvea, R. Hamdi, M. Hendry, M. Kanda, T. Kawai, Y. Kawamoto, H. Kondo, E. S. Krayenhoff, S. H. Lee, T. Loridan, A. Martilli, V. Masson, S. Miao, K. Oleson, R. Ooka, G. Pigeon, A. Porson, Y. H. Ryu, F. Salamanca, G. J. Steeneveld, M. Tombrou, J. A. Voogt, D. T. Young 
\& N. Zhang (2011) Initial results from Phase 2 of the international urban energy balance model comparison. International Journal Of Climatology, 31, 244-272.

Harman, I. N. \& S. E. Belcher (2006) The surface energy balance and boundary layer over urban street canyons. Quarterly Journal of the Royal Meteorological Society, 132, 2749-2768.

Kanda, M., T. Kawai, M. Kanega, R. Moriwaki, K. Narita \& A. Hagishima (2005) A Simple Energy Balance Model for Regular Building Arrays. Boundary-Layer Meteorology, 116, 423-443.

Krayenhoff, E. \& J. Voogt (2007) A microscale three-dimensional urban energy balance model for studying surface temperatures. Boundary-Layer Meteorology, 123, 433-461.

Kusaka, H. \& F. Kimura (2004) Thermal Effects of Urban Canyon Structure on the Nocturnal Heat Island: Numerical Experiment Using a Mesoscale Model Coupled with an Urban Canopy Model. Journal Of Applied Meteorology, 43, 1899-1910.

Kusaka, H., H. Kondo, Y. Kikegawa \& F. Kimura (2001) A Simple Single-Layer Urban Canopy Model For Atmospheric Models: Comparison With Multi-Layer And Slab Models. Boundary-Layer Meteorology, 101, 329-358.

Lemonsu, A., V. Masson, L. Shashua-Bar, E. Erell \& D. Pearlmutter (2012) Inclusion of vegetation in the Town Energy Balance model for modelling urban green areas. Geosci. Model Dev., 5, 1377-1393.

Lindberg, F. (2005) Towards the use of local governmental 3-d data within urban climatology studies. Mapping and Image Science, 2, 32-37.

Lindberg, F. (2007) Modelling the urban climate using a local governmental geo-database. Meteorological Applications, 14, 263-273.

Lindberg, F. \& C. S. B. Grimmond (2010) Continuous Sky View Factor Maps from High Resolution Urban Digital Elevation Models. Climate Research, 42, 177-183.

Lindberg, F. \& C. S. B. Grimmond (2011) Nature of vegetation and building morphology characteristics across a city: Influence on shadow patterns and mean radiant temperatures in London. Urban Ecosystems, 14, 617-634.

Lindberg, F., B. Holmer \& S. Thorsson (2008) SOLWEIG 1.0 - Modelling spatial variations of 3D radiant fluxes and mean radiant temperature in complex urban settings. International Journal of Biometeorology, 52, 697713.

Loridan, T. \& C. S. B. Grimmond (2012) Characterization of Energy Flux Partitioning in Urban Environments: Links with Surface Seasonal Properties. Journal of Applied Meteorology and Climatology, 51, 219-241.

Loridan, T., F. Lindberg, O. Jorba, S. Kotthaus, S. Grossman-Clarke \& C. S. B. Grimmond (2013) High Resolution Simulation of the Variability of Surface Energy Balance Fluxes Across Central London with Urban Zones for Energy Partitioning. Boundary-Layer Meteorology, 1-31.

Martilli, A. (2009) On the Derivation of Input Parameters for Urban Canopy Models from Urban Morphological Datasets. Boundary-Layer Meteorology, 130, 301-306.

Martilli, A., A. Clappier \& M. Rotach (2002) An Urban Surface Exchange Parameterisation for Mesoscale Models. Boundary-Layer Meteorology, 104, 261-304.

Masson, V. (2000) A Physically-Based Scheme For The Urban Energy Budget In Atmospheric Models. BoundaryLayer Meteorology, 94, 357-397.

Ordnance_Survey. 2010. (C) Crown database right 2010. An Ordnance Survey/EDINA supplied service.

Ratti, C. F. (2005) The lineage of the line: space syntax parameters from the analysis of urban DEMs. Environment and Planning B-Planning \& Design, 32, 547-566.

Ratti, C. F. \& P. Richens. 1999. Urban texture analysis with image processing techniques. In Proc CAADFutures99. Atalanta, GA.

Ratti, C. F. \& P. Richens (2004) Raster analysis of urban form. Environment and Planning B-Planning \& Design, 31, 297-309.

Schubert, S., S. Grossman-Clarke \& A. Martilli (2012) A Double-Canyon Radiation Scheme for Multi-Layer Urban Canopy Models. Boundary-Layer Meteorology, 145, 439-468.

Schubert, S. and Grossman-Clarke, S., 2013. The Influence of green areas and roof albedos on air temperatures during Extreme Heat Events in Berlin, Germany. Meteorol. Z., 22(2): 131-143.

Stewart, I.D. and Oke, T.R., 2012. Local Climate Zones for Urban Temperature Studies. Bulletin of the American Meteorological Society, 93(12): 1879-1900.

Thorsson, S., F. Lindberg, J. Bjorklund, B. Holmer \& D. Rayner (2011) Potential changes in outdoor thermal comfort conditions in Gothenburg, Sweden due to climate change: the influence of urban geometry. International Journal Of Climatology, 31, 324-335. 
Yu, B., H. Liu, J. Wu \& W.-M. Lin (2009) Investigating impacts of urban morphology on spatio-temporal variations of solar radiation with airborne LIDAR data and a solar flux model: a case study of downtown Houston. International Journal of Remote Sensing, 30, 4359 - 4385. 


\section{FIGURES AND CAPTIONS}

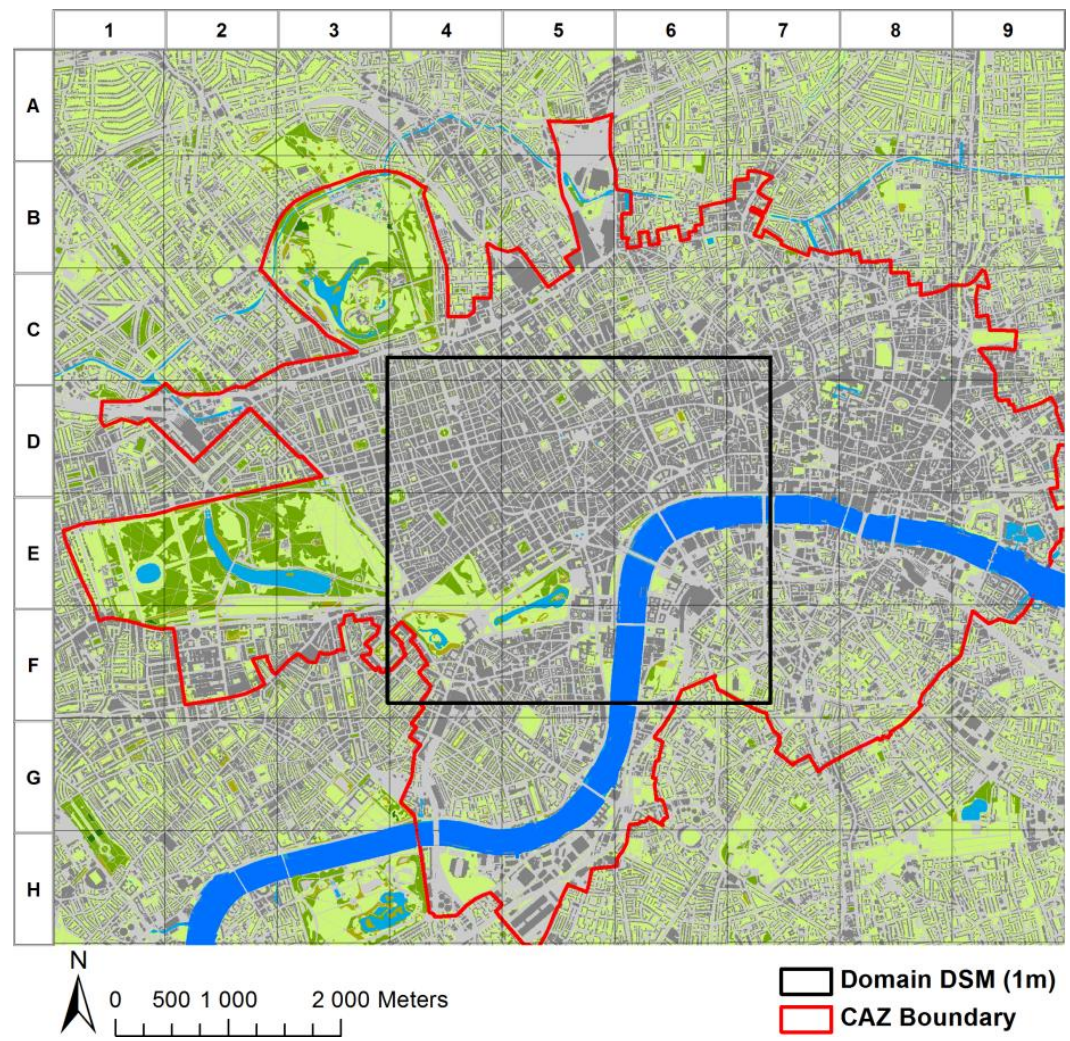

Figure 1: The Central Activity Zone (CAZ) within London, UK with a $1 \mathrm{~km}^{2}$ grid overlain. Source: OS MasterMap ${ }^{\circledR}$ Topography Layer (Ordnance Survey, 2010). Domain DSM (1 m) shows the domain of the DSM derived from a LiDAR dataset gridded at $1 \mathrm{~m}$ resolution.
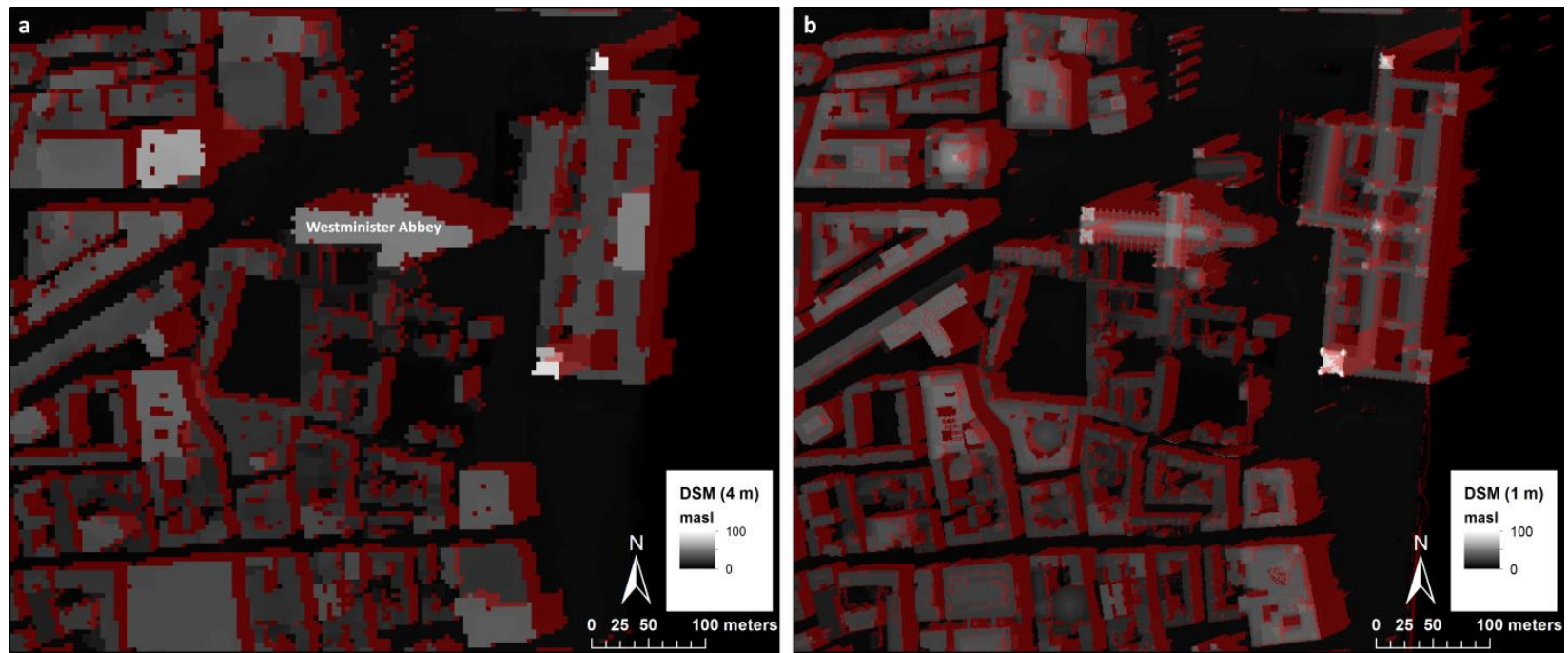

Figure 2: Digital surface models derived from a) Virtual London dataset (4 $\mathrm{m}$ resolution) and b) NERC/ARSF LiDAR dataset (1 $\mathrm{m}$ resolution) for the area around Westminster Abbey and Houses of Parliament in London from the two datasets used to generate the sunlit fractions. Red areas show shadow patterns at 16:00 on the $21^{\text {st }}$ of June (DOY=172). 


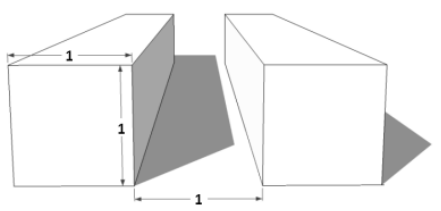

b
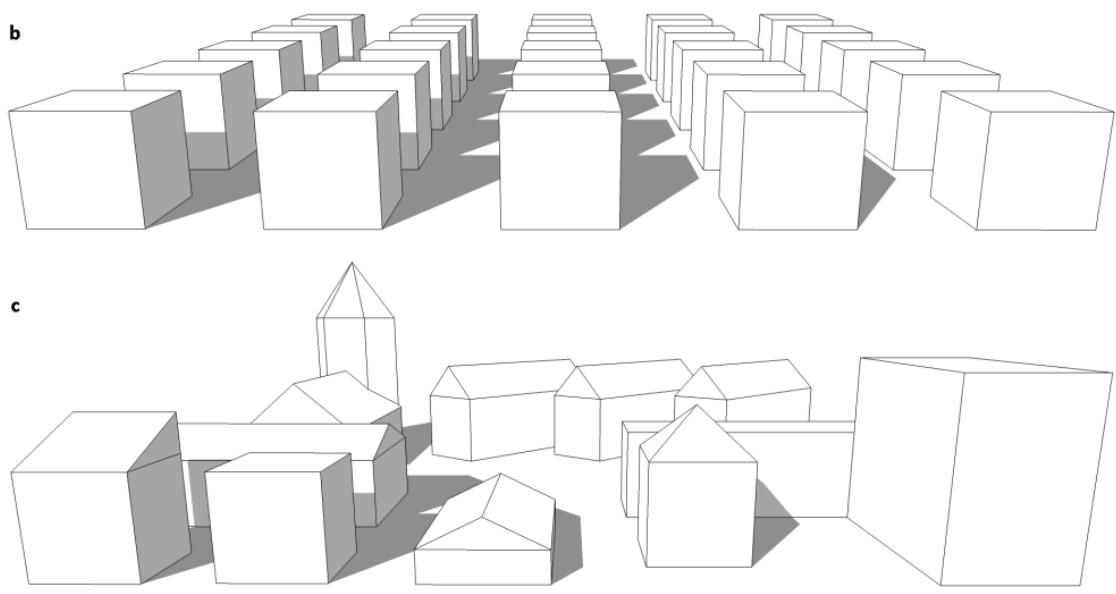

Figure 3: Three different simplifications of urban form represented by a) an infinite long canyon, b) regular arrays of cubes, c) near real world geometry. 


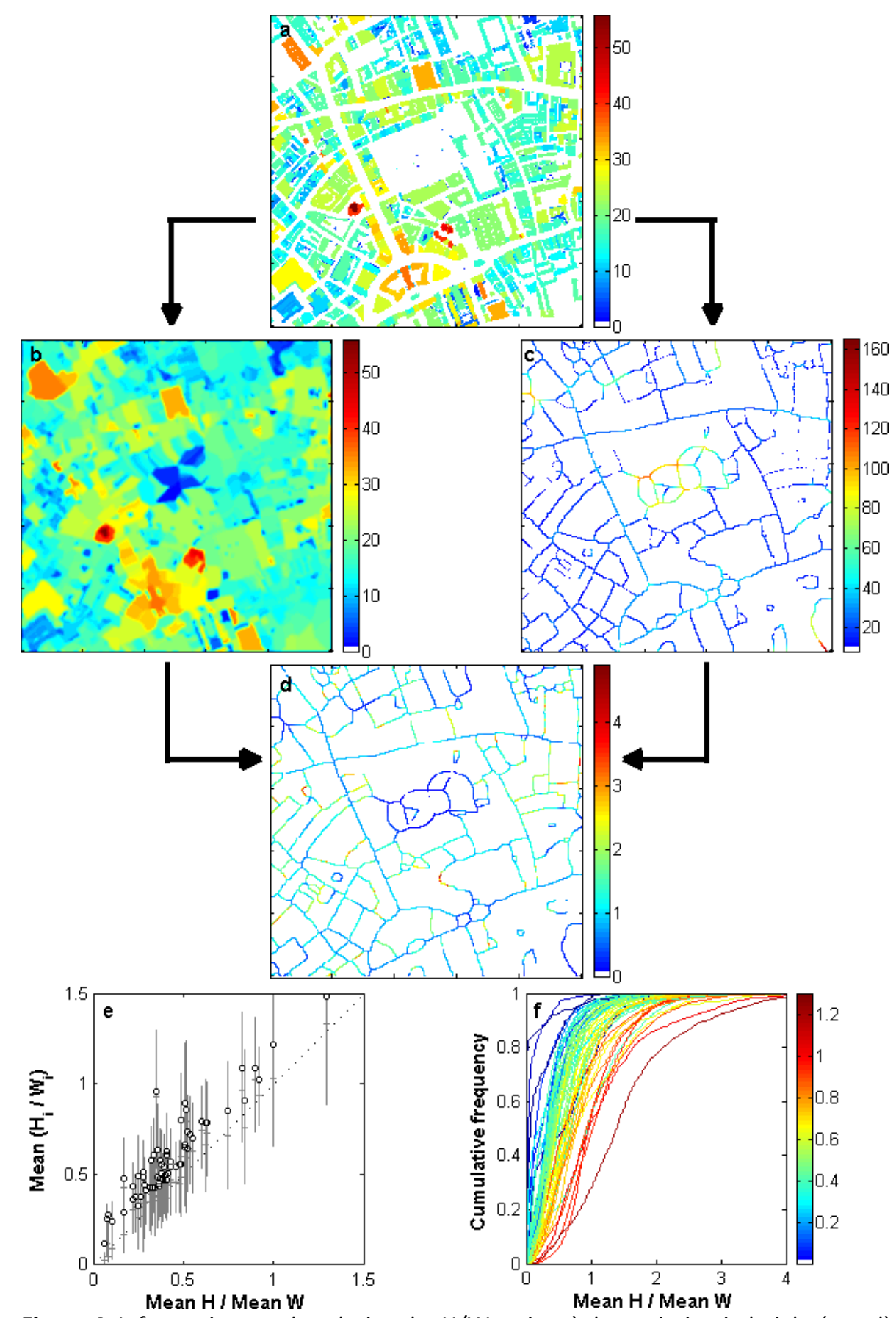

Figure 4: Information used to derive the H/W-ratio. a) the variation in height ( $\mathrm{m}$ agl) within a $1 \mathrm{~km}^{2} \mathrm{area}(4 \mathrm{~m}$ resolution DSM, see section 2 ) in central London, b) allocated building heights ( $\mathrm{m}$ agl) on ground pixels $\mathbf{c}$ ) street width in meters at local maxima in between buildings (text for detailed explanation), d) the variation in [H/W] ratio based on the local maxima (the $i$ values in Eq. 2, see text for detailed explanation); note that the same locations will also provide the width used in Eq. 1, e) H/W-ratio (Eq. 1) versus H/W-ratio (Eq. 2) for all 72 of the $1 \mathrm{~km}^{2}$ grids used in this study (o=average; - =median; line represents $25 \%$ and $75 \%$ quartiles) and f) frequency distribution of H/W-ratios using Eq. 2 for all the $1 \mathrm{~km}^{2}$ grids used in this study ( 0.2 bins of $\mathrm{H} / \mathrm{W}$ ratio are used). Lines are coloured based in H/W-ratio (Eq. 1). 


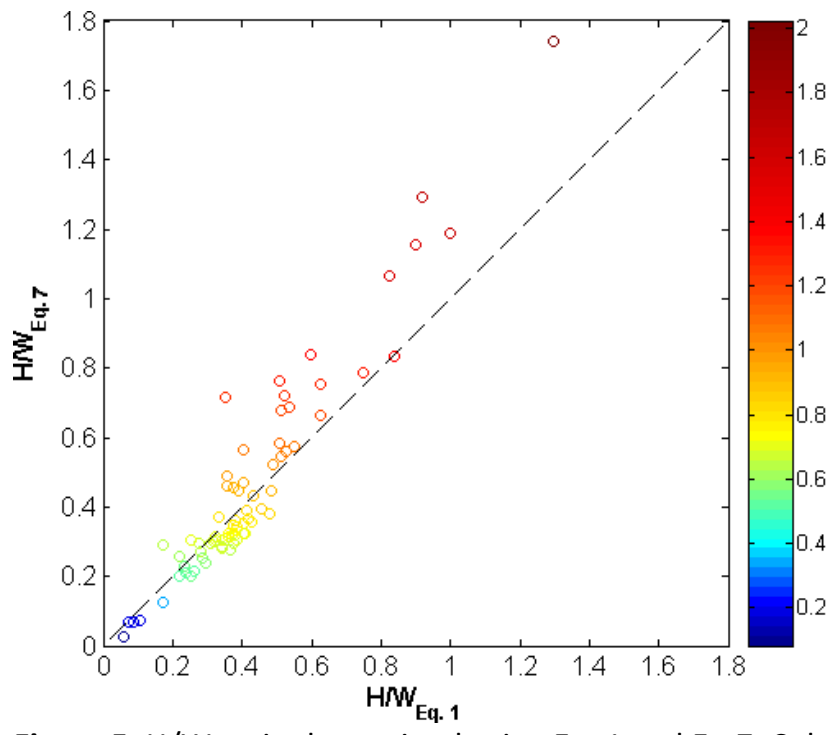

Figure 5: H/W-ratio determined using Eq. 1 and Eq.7. Colours based on total facet area / horizontal area (1 $\left.\mathrm{km}^{2}\right)$.

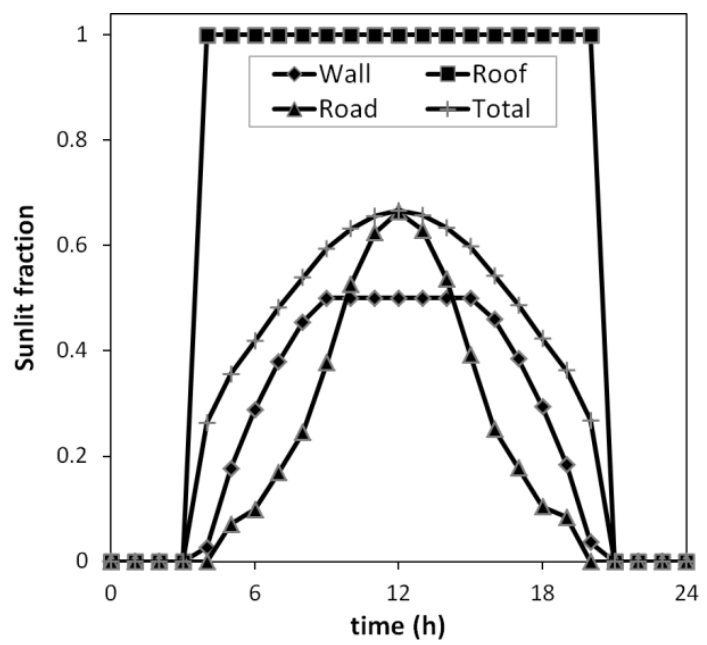

Figure 6: Fractions of total, roof, road, and wall surfaces (relative to their individual facet areas) that are sunlit for each hour of $21^{\text {st }}$ June $(D O Y=172)$ in London for an ILC (H/W=1) using the SLUCM approach (Kusaka et al. 2001). 

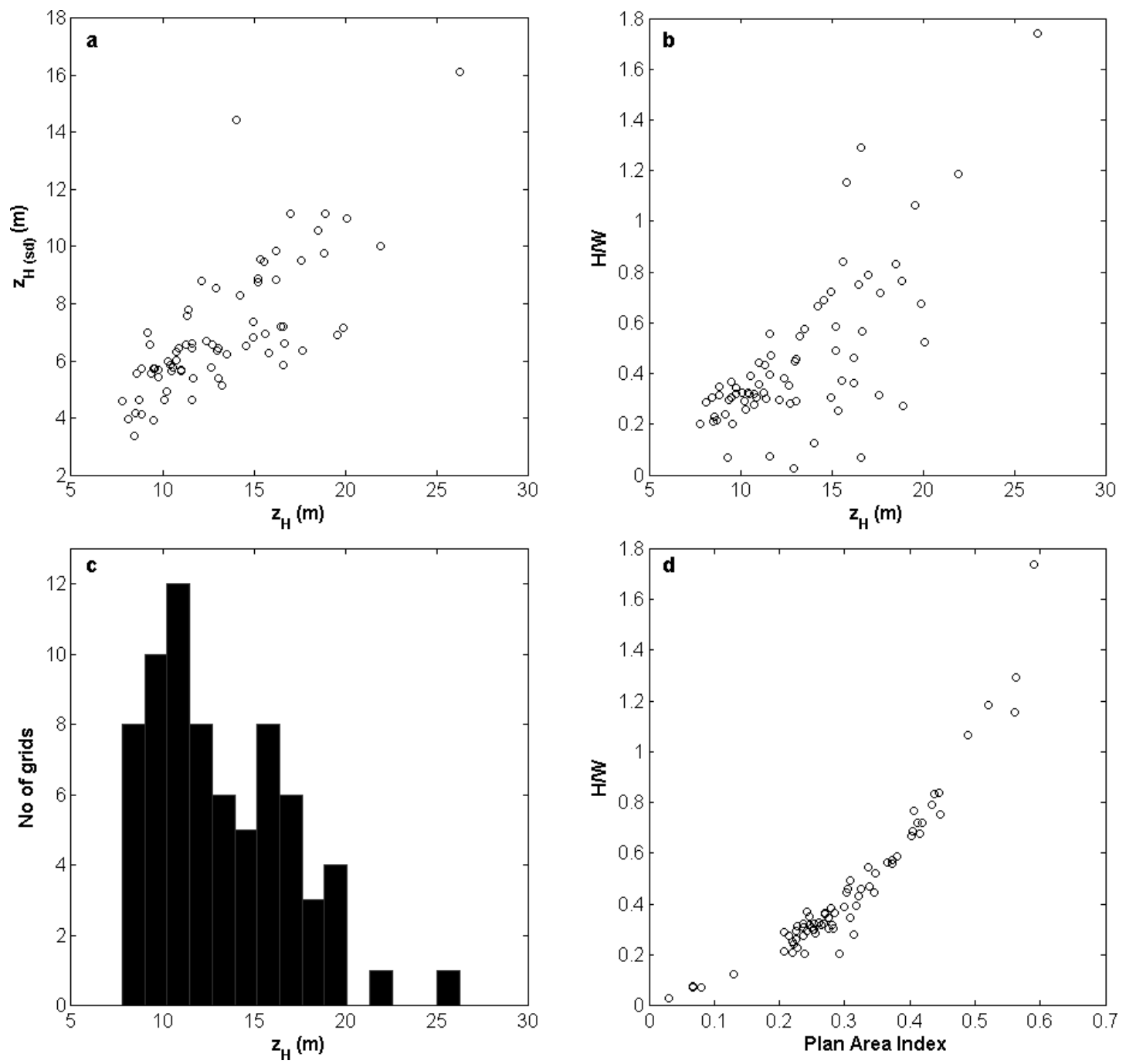

Figure 7: For the $72,1 \mathrm{~km}^{2}$ grids the building mean heights $(\mathrm{zH})(\mathrm{a})$ versus standard deviations $(\mathrm{zH}(\mathrm{sd}))$, b) versus height to width ratio $(H / W)$ (eq. 7), c) $z_{H}$ frequency distribution and the d) plan area index $\left(\lambda_{P}\right)$ versus $H / W$. 

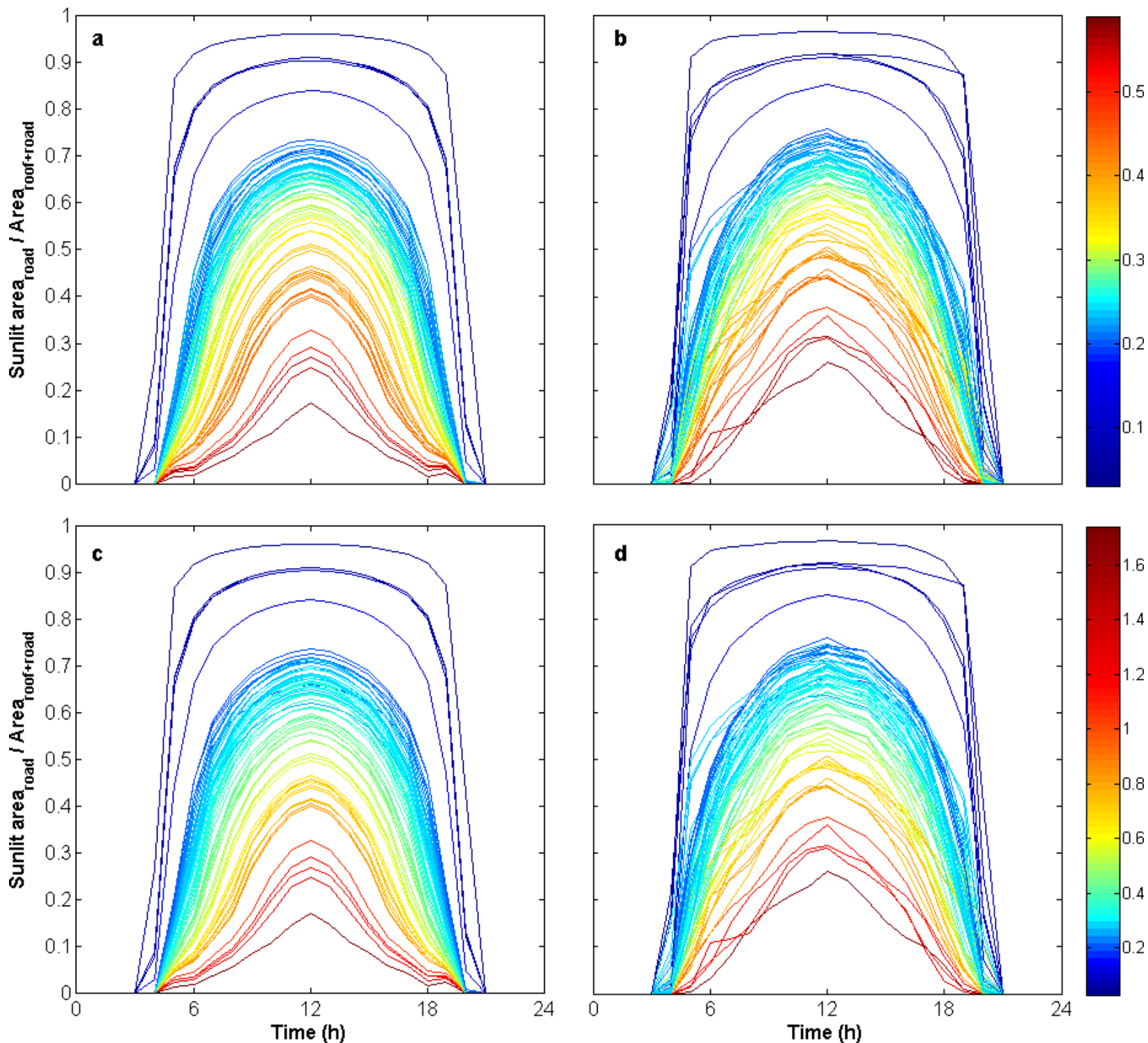

Figure 8: Sunlit area on roads (DOY=172) as a fraction of total area of roads and roofs for each of the 72 grids (1 $\mathrm{km}^{2}$ ) within the study area (Figure 1) using the (left) SLUCM scheme and (right) the SCA on the Virtual London dataset gridded at $4 \mathrm{~m}$ resolution. Colours based on (upper row) plan area index ( $\lambda_{\mathrm{P}}$ ) and (lower) H/W-ratio. a) $\operatorname{SLUCM}_{(\lambda p)}$, b) Virtual London( $(\lambda p)$, c) $\operatorname{SLUCM}_{(H / W)}$, d) Virtual London(H/W). 

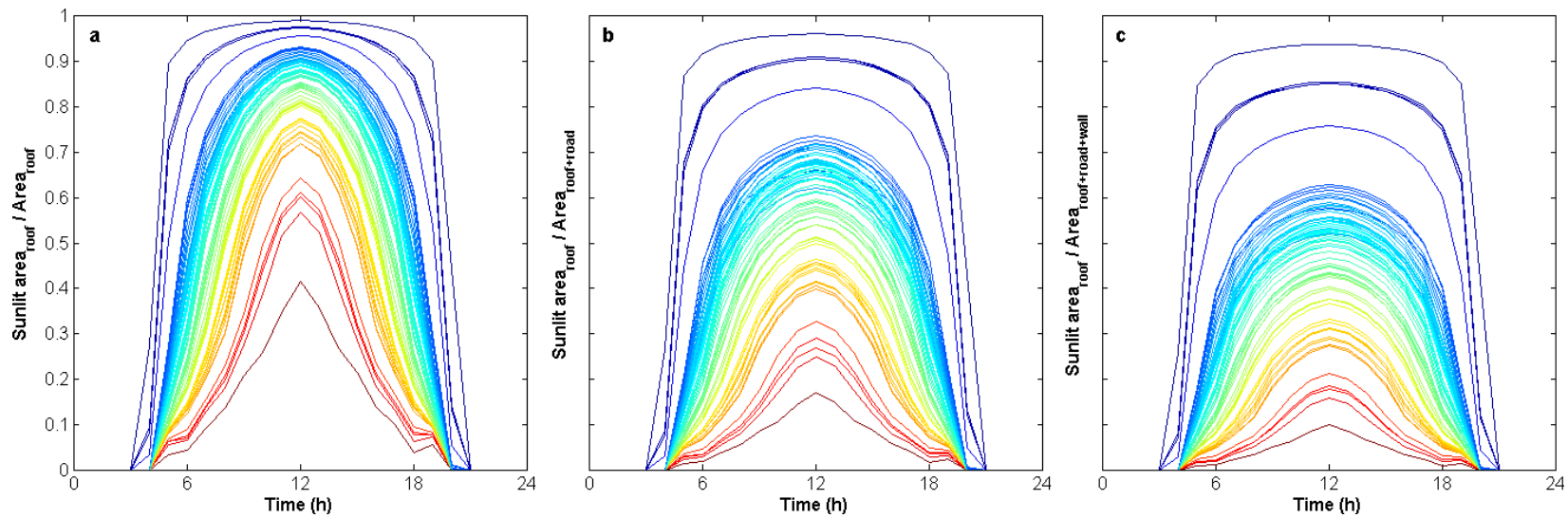

Figure 9: Sunlit area on roads ( $D O Y=172$ ) as a fraction of the different total areas within the grid: a) roads, b) roads and roofs (Figure $8 \mathrm{a}$ ) and c) roads, roofs and walls for each of the 72 grids $\left(1 \mathrm{~km}^{2}\right)$ within the study area using the SLUCM scheme on the Virtual London dataset gridded at $4 \mathrm{~m}$ resolution. Colours based on the plan area index $\left(\lambda_{P}\right)$ colour scheme used in Figure 8 upper.
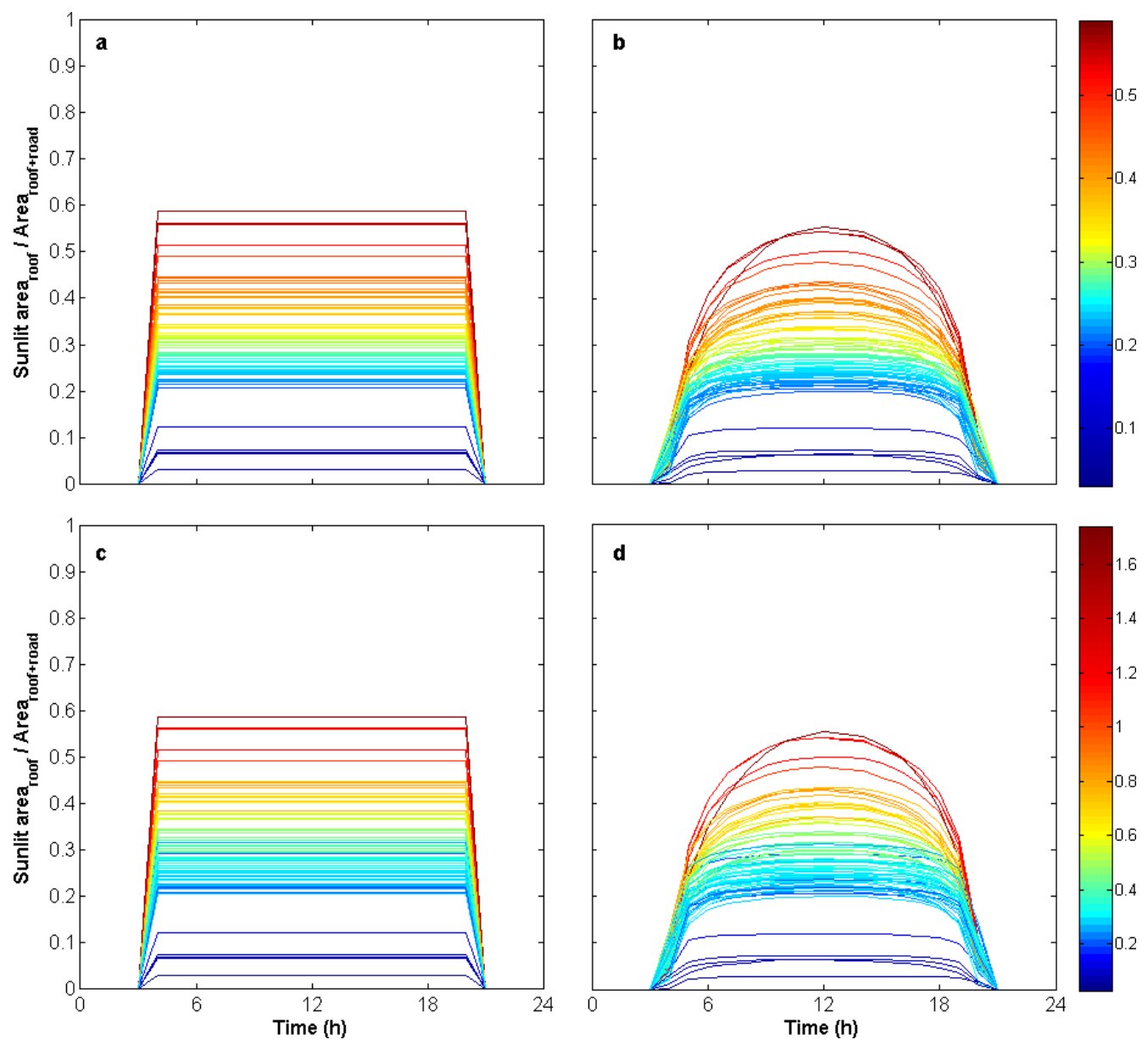

Figure 10: Sunlit area on roofs (DOY=172) as a fraction of total area of roads and roofs for each of the 72 grids (1 $\mathrm{km}^{2}$ ) within the study area (Figure 1 and 4) using (left) SLUCM and (right) SCA on the Virtual London dataset gridded at $4 \mathrm{~m}$ resolution. Colours based on (upper row) plan area index ( $\left.\lambda_{P}\right)$ and (lower) H/W-ratio. a) $\operatorname{SLUCM}_{(\lambda P)}$, b) Virtual London( $(\lambda P)$, c) $\operatorname{SLUCM}_{(H / W)}$, d) Virtual London(H/W). 


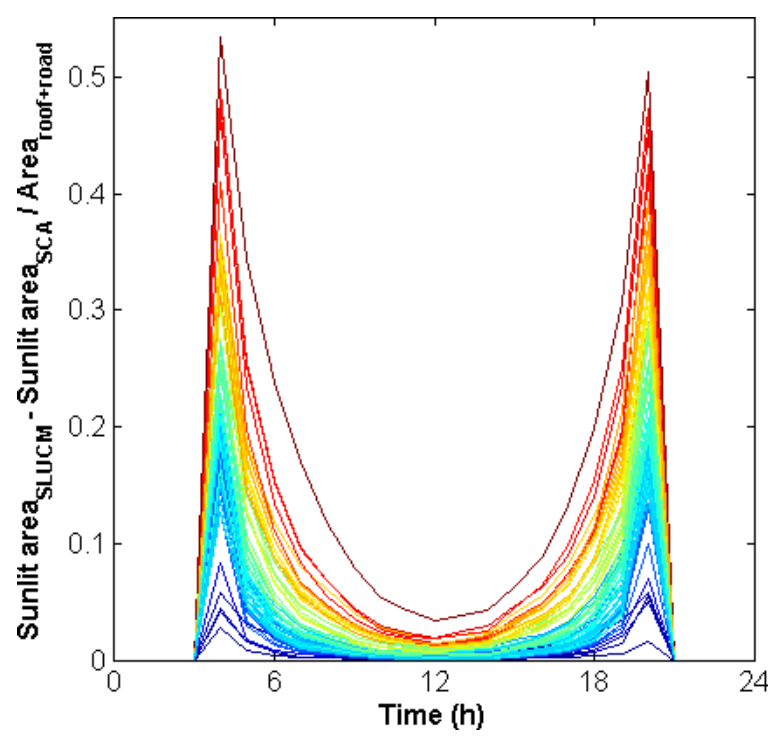

Figure 11: Difference in sunlit area on roofs (SLUCM-SCA) as a fraction of total area of roads and roofs for each of the 72 grids (1 km2) within the study area (Figure 1 and 4). Colours based on (lower) H/W-ratio in Figure 10.

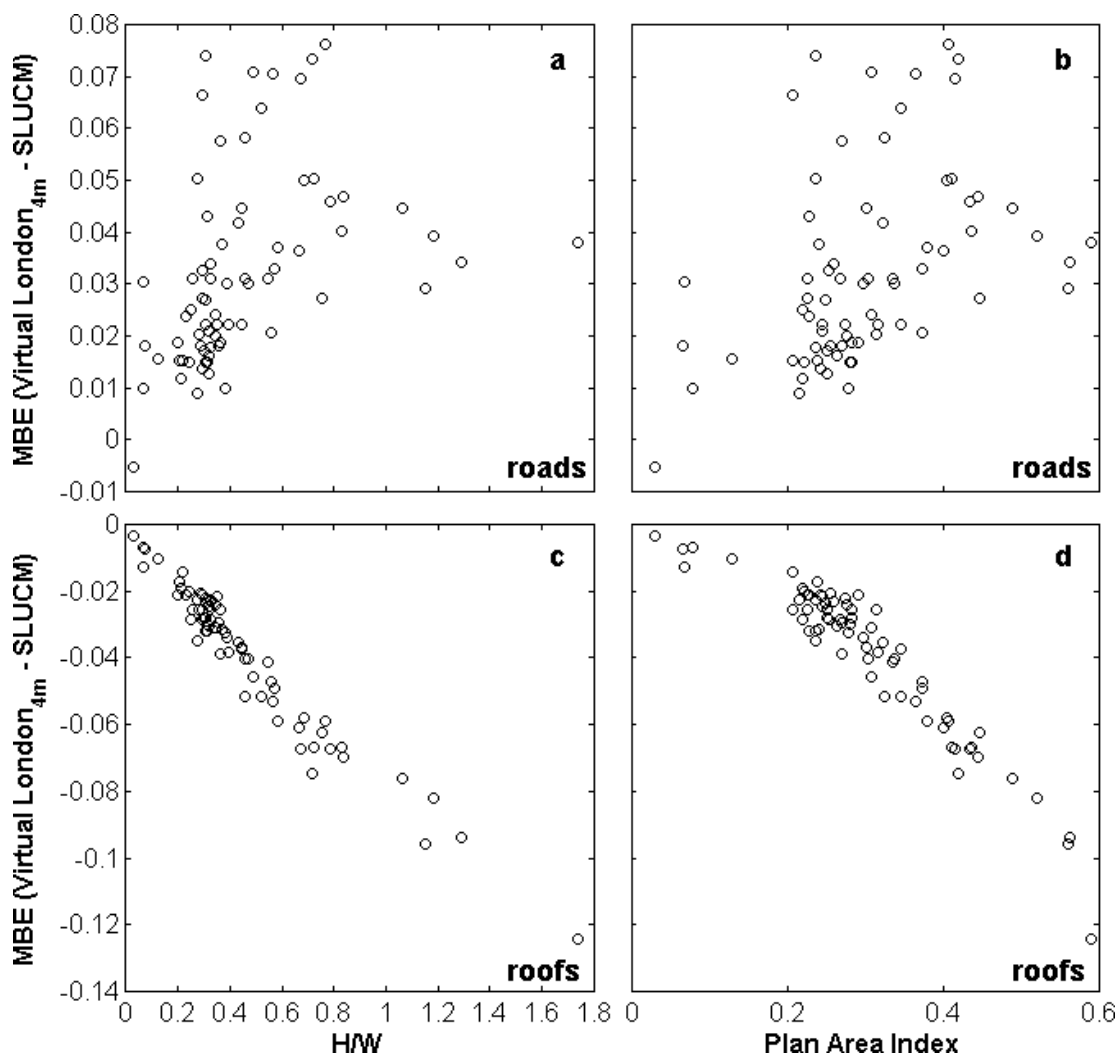

Figure 12: Mean bias errors (MBE) (SCA DSM(4m) - SLUCM) for daytime sunlit fractions (DOY 172) on roads versus a) plan area index b) $\mathrm{H} / \mathrm{W}$ and roofs versus a) plan area index and $\mathbf{b}$ ) $\mathrm{H} / \mathrm{W}$ ratio for the $72,1 \mathrm{~km}^{2}$ grids. Note difference in $\mathrm{Y}$-axes between roads and roofs 

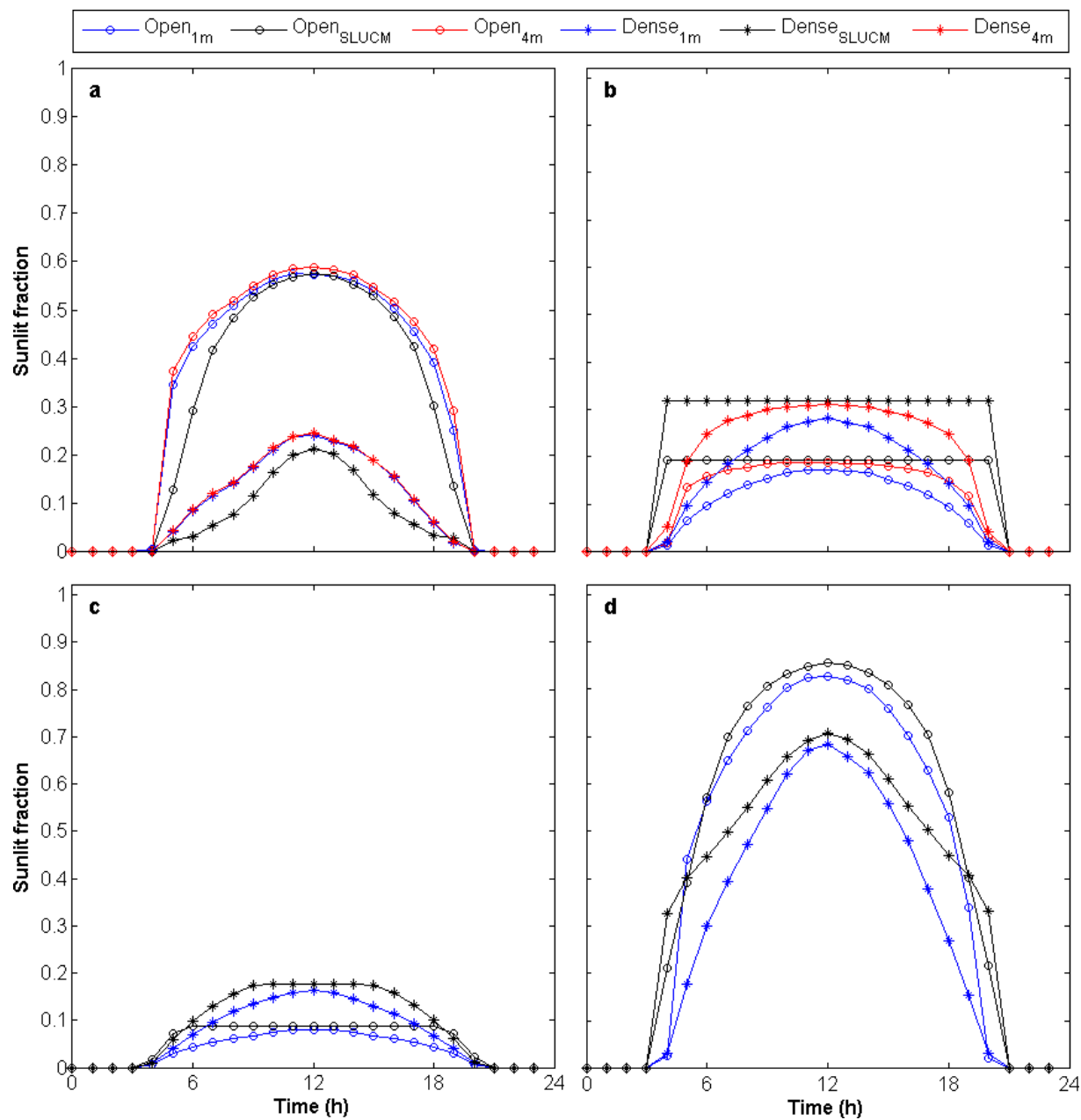

Figure 13: Sunlit fractions related to total urban area (roof+roads+walls) on a) roads, b) roofs, c) walls and d) total for two $1 \mathrm{~km}$ grids (Figure 1, 6D and 6E) using the SLUCM, the SCA with the $4 \mathrm{~m}$ resolution DSM and the SCA and $1 \mathrm{~m}$ DSM (DOY=172). 


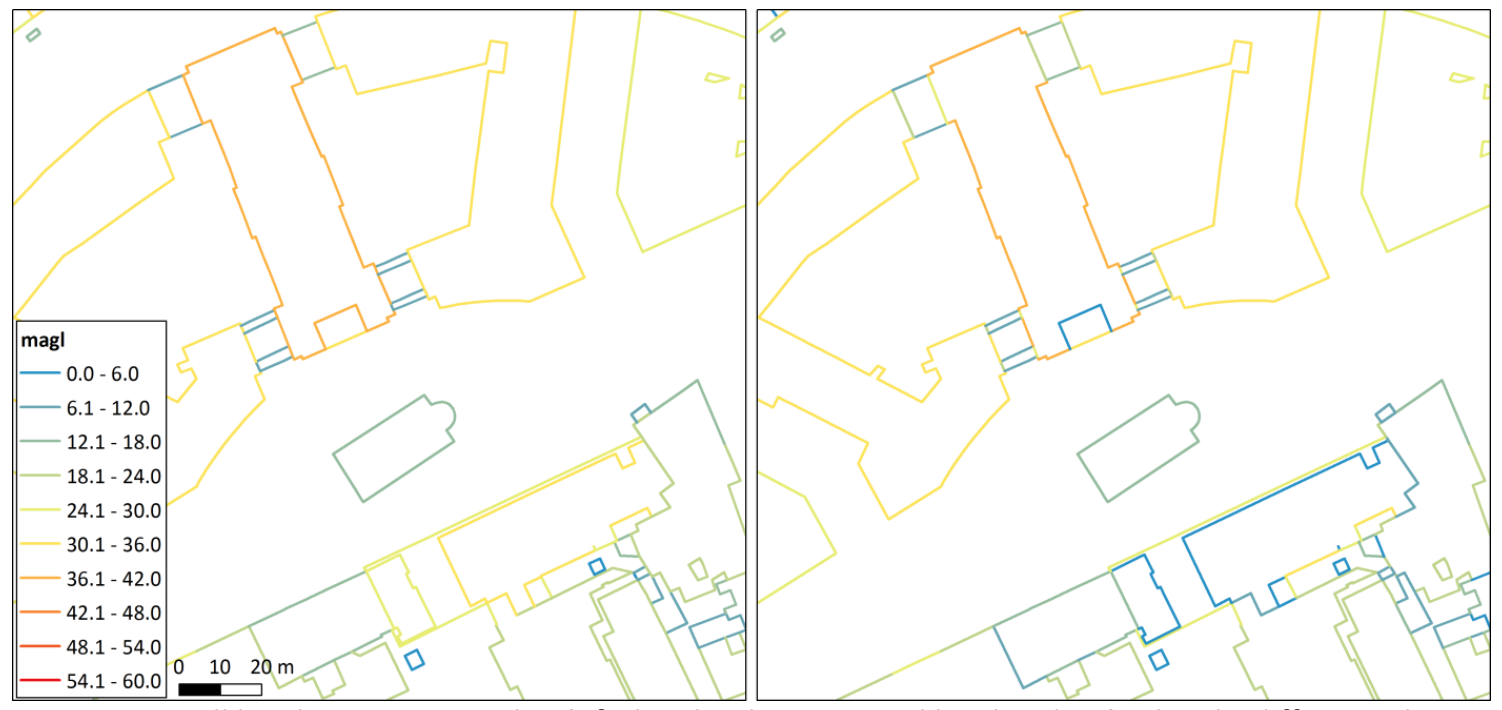

Figure A1: Wall heights represented as left; height above ground level and right; height difference between ground or adjacent building.

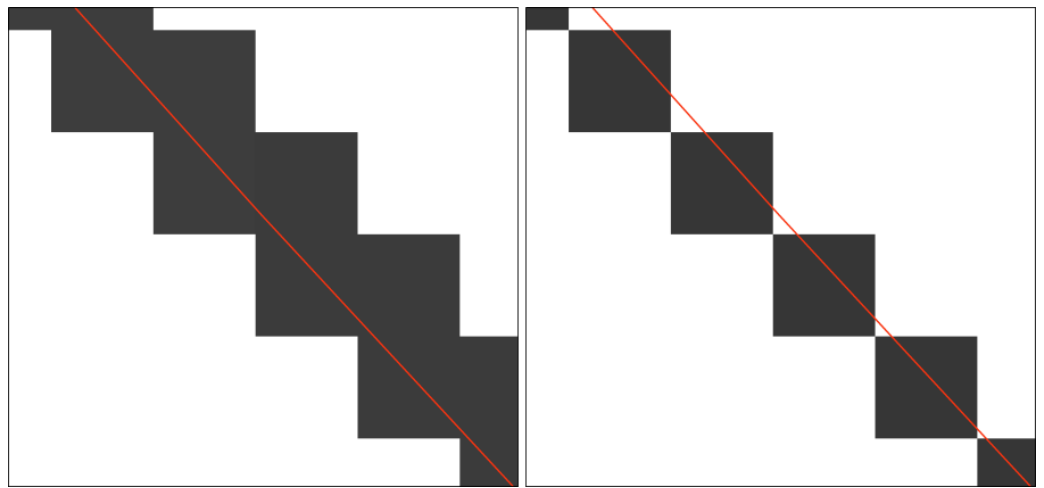

Figure A2: Raster representation of a building wall (gray) based on a vector line (red), left; using a regular vector to raster converter and right; using a 4-direction maximum $3 \times 3$ kernel filter.
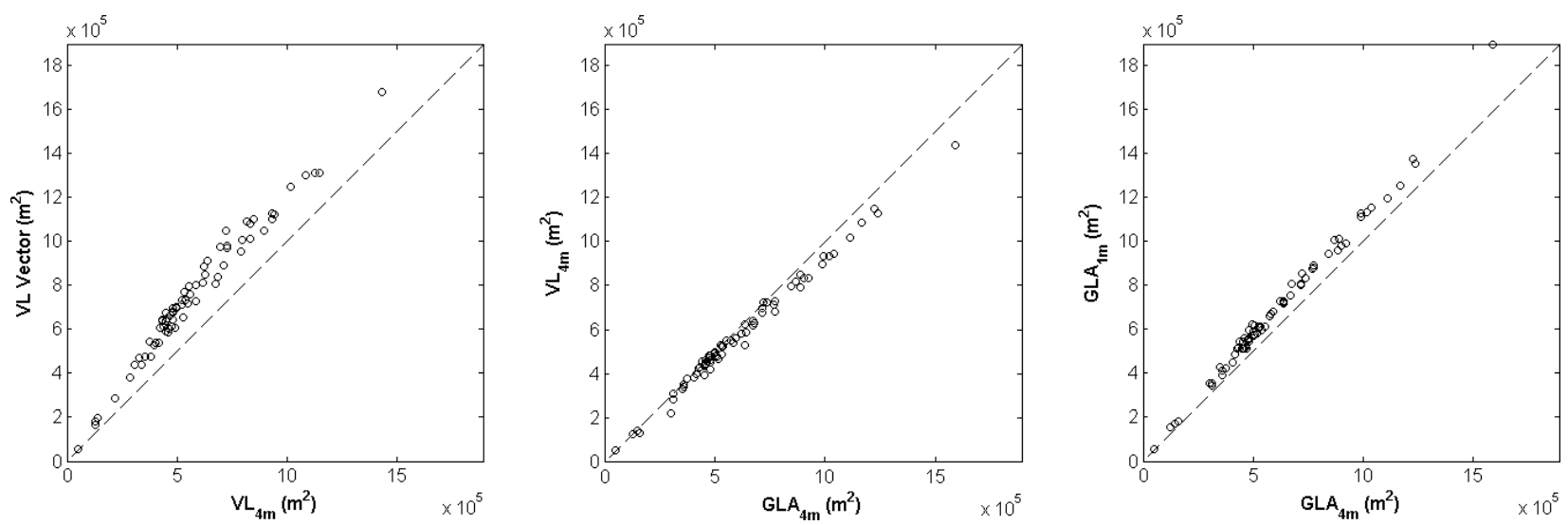

Figure A3: Comparision of estimated wall area for all of the $721 \mathrm{~km}^{2}$ grids used in this study using different data formats and spatial resolution. Wall areas are derived using i) Virtual London vector data (VL Vector), ii) rasterized Virtual London vector data at $4 \mathrm{~m}$ resolution $\left(\mathrm{VL}_{4 \mathrm{~m}}\right)$ and iii) rasterised LiDAR data from Greater London Authority (GLA) at $1 \mathrm{~m}$ resolution $\left(G L A_{1 m}\right)$ and resampled to $4 \mathrm{~m}$ using a nearest neighbor methodology $\left(G_{4} 4 m\right)$. 